\title{
Manic and Depressive Symptoms in Children Diagnosed with Noonan Syndrome
}

\author{
Paolo Alfieri ${ }^{1, *,+}{ }^{\mathbb{D}}$, Francesca Cumbo ${ }^{1,+}{ }^{,}$Giulia Serra ${ }^{1}$, Monia Trasolini ${ }^{1}$, Camilla Frattini ${ }^{1}$, \\ Francesco Scibelli ${ }^{1}{ }^{\complement}$, Serena Licchelli ${ }^{1,2}$, Flavia Cirillo ${ }^{1}$, Cristina Caciolo ${ }^{1}$, Maria Pia Casini ${ }^{1,3}$, Adele D’Amico ${ }^{4}$, \\ Marco Tartaglia ${ }^{5}$, Maria Cristina Digilio ${ }^{5}$, Rossella Capolino ${ }^{5}$ and Stefano Vicari ${ }^{1,6}$
}

1 Child and Adolescent Psychiatry Unit, Department of Neuroscience, Bambino Gesù Children's Hospital, IRCCS, 00165 Rome, Italy; francesca.cumbo@opbg.net (F.C.); giulia.serra@opbg.net (G.S.); monia.trasolini@opbg.net (M.T.); cmllfrt@gmail.com (C.F.); francesco.scibelli@opbg.net (F.S.); serena.licchelli@gmail.com (S.L.); flavia.cirillo@opbg.net (F.C.); cristina.caciolo@opbg.net (C.C.); m.casini@policlinicoumberto1.it (M.P.C.); stefano.vicari@opbg.net (S.V.)

2 Fondazione UILDM Lazio Onlus, 00167, Rome, Italy

3 Section of Child and Adolescent Neurology and Psychiatry, Department of Human Neuroscience, Sapienza University of Rome, 00161 Rome, Italy

4 Unit of Neuromuscular and Neurodegenerative Disorders, Department of Neuroscience, Bambino Gesù Children's Hospital, IRCCS, 00165 Rome, Italy; adele2damico@opbg.net

5 Genetics and Rare Diseases Research Division, Bambino Gesù Children's Hospital, IRCCS, 00146 Rome, Italy; marco.tartaglia@opbg.net (M.T.); mcristina.digilio@opbg.net (M.C.D.); rossella.capolino@opbg.net (R.C.)

6 Department of Life Sciences and Public Health, Università Cattolica del Sacro Cuore, 00168 Rome, Italy

* Correspondence: paolo.alfieri@opbg.net; Tel.: +39-0668594721

+ These authors contributed equally.

Citation: Alfieri, P.; Cumbo, F.; Serra, G.; Trasolini, M.; Frattini, C.; Scibelli, F.; Licchelli, S.; Cirillo, F.; Caciolo, C.; Casini, M.P.; et al. Manic and Depressive Symptoms in Children Diagnosed with Noonan Syndrome. Brain Sci. 2021, 11, 233. https:// doi.org/10.3390/brainsci11020233

Academic Editor: Atsumi Nitta

Received: 24 December 2020

Accepted: 8 February 2021

Published: 13 February 2021

Publisher's Note: MDPI stays neutral with regard to jurisdictional claims in published maps and institutional affiliations.

\begin{abstract}
Noonan syndrome (NS) is a dominant clinically variable and genetically heterogeneous developmental disorder caused by germ-line mutations encoding components of the Ras-MAPK signaling pathway. A few studies have investigated psychopathological features occurring in individuals with NS, although they were poorly analyzed. The aim of the present work is to investigate the psychopathological features in children and adolescents with NS focusing on depressive and hypo-manic symptoms. Thirty-seven subjects with molecularly confirmed diagnosis were systematically evaluated through a psychopathological assessment. In addition, an evaluation of the cognitive level was performed. Our analyses showed a high recurrence of attention deficit and hyperactivity disorder symptoms, emotional dysregulation, irritability, and anxiety symptomatology. The mean cognitive level was on the average. The present study provides new relevant information on psychopathological features in individuals with NS. The implications for clinicians are discussed including the monitoring of mood disorders in a clinical evolution.
\end{abstract}

Keywords: psychopathological features; attention deficit and hyperactivity disorder; deficient emotional self-regulation; irritability; anxiety traits; mood

\section{Introduction}

Noonan syndrome (NS) is a clinically variable and genetically heterogeneous disorder affecting development and growth. Major features include a distinctive facial appearance, short stature, congenital cardiac defects, pulmonary valve stenosis most commonly, and hypertrophic cardiomyopathy $(\mathrm{HCM}, 10-20 \%)$ as well as variable cognitive deficits [1-4]. NS is considered as one of the most common non-chromosomal disorders affecting neurodevelopment.

NS is caused by germ-line mutations in genes encoding components of the Ras-MAPK signaling pathway [4]. In approximately $50 \%$ of cases, it is caused by dominant mutations in PTPN11 [5]. Heterozygous activating mutations in SOS1, RAF1, and RIT1 also represent relatively common events, while an increasing number of genes (e.g., NRAS, $S O S 2, R R A S 2$, and MRAS) have been reported to account for a relatively small proportion 
of cases [6-9]. In a significant proportion of patients with NS, loss-of-function (recessive form) or dominant negative (dominant form) mutations in LZTR1 have been reported. NS is clinically related to other developmental disorders collectively denominated "RASopathies", sharing the upregulation of the Ras-MAPK signaling cascade as a mechanism of disease [10-12]. Among these, Costello syndrome (CS), cardiofaciocutaneous syndrome (CFCS), Noonan syndrome with multiple lentigines (NSML, formerly known as LEOPARD syndrome), Mazzanti syndrome (MS), neurofibromatosis type 1, and Legius syndrome have been characterized [13]. New conditions are also emerging [10]. In RASopathies, a cognitive deficit significantly varies depending on the gene involved and the type of mutation. Most patients with NS show an intellectual cognitive profile in the low/average range [14-16]. While some studies described a relatively low occurrence of intellectual disability (11\% of cases) in SOS1 patients with respect to the NS general population [17,18], other significant genotype-phenotype correlations and relatively other neuropsychiatric features are less clear, probably due to the relatively small size of the cohorts analyzed [19]. Psychopathological features of individuals with NS have also been investigated, and a relatively higher risk of psychiatric diseases when compared to the control population have been reported [20-23]. Mood disorders, social problems, communication difficulties, executive functioning impairment, and attention deficit have been listed as major features $[20,24,25]$.

During adulthood, individuals diagnosed with NS struggle with well-known socialization and daily living problems, including difficulties with maintaining employment and typical social relationships $[1,21]$. Some cases of psychiatric disorders (mostly in subjects with mild cognitive deficits), such as bipolar affective disorder [21,26], schizophrenia [21,27], panic disorder, and alexithymia [21,28], have been reported.

Recent works [29] confirmed emotional and internalizing dysfunctions using a selfreport questionnaire in adults with NS. Some studies highlighted high levels of demoralization in adults with NS, presumably due to the burden of chronic disorder. Furthermore, authors found low levels of life satisfaction (including a high percentage of bullying episodes in childhood). Broadly speaking, individuals with NS showed an introvert personality style combined with internalizing difficulties. Moreover, other studies reported a that a high percentage of depression and anxiety disorders is estimated in $49 \%$ of subjects diagnosed with NS [4,30,31].

Less is known about affective disorders in NS in childhood. It is well established that children and adolescences with NS mostly suffer from attention deficit and hyperactivity (ADHD) symptoms (up to 40-50\%) [19,25,32]. Individuals with ADHD generally appear as highly impulsive with difficulties in self-regulatory functions and in emotional regulation $[33,34]$. The emotional regulation is the ability to "(a) inhibit inappropriate behavior related to strong negative or positive emotions, (b) self-soothe any physiological arousal that the strong affect has induced, (c) refocus attention, and (d) organize for coordinated action in the service of an external goal $[35,36]^{\prime \prime}$. Furthermore, patients with ADHD often show a range of affective symptoms such as emotional instability, impulsivity, agitation, restlessness, and mood dysregulation [37]. In order to plan an appropriate treatment and inform patients and their parents about the psychopathological development and long term prognosis affective symptoms during childhood in NS, characterizing mood dysregulation in juvenile subjects as a typical of ADHD or as a separate psychiatric condition would be very interesting $[36,38]$.

Several studies [39-42] analyzed emotional dysregulation using the Child Behavior Checklist (CBCL)-AAA profile [36]. This score, calculated as the sum of Anxious/Depressed, Attention, and Aggression, is a widely used assessment for the Deficient Emotional SelfRegulation (DESR) evaluation which has been frequently identified in ADHD subjects showing severe forms of mood and behavioral dysregulation [37,39].

Our previous findings [43] also showed affective and behavioral dysregulation symptoms as measured using the CBCL-AAA profile in children diagnosed with RASopathies (mainly NS). Several studies underlined a strong overlap between the ADHD and anxious- 
depressive features among children diagnosed with RASopathies, mainly among NS subjects [44-46]. Despite that, little is known about the presence of mood and anxiety symptoms in individuals with NS.

The aim of the present study is to investigate the prevalence and severity of depressive, dysphoric/mixed, and (hypo)manic features in a cognitively assessed sample of 37 subjects with NS using a neuropsychiatric evaluation, parent-report questionnaire, and semi-structured interviews according to the Diagnostic and Statistical Manual of Mental Disorders, fourth edition, text revision (DSM-IV-TR) criteria [47].

\section{Materials and Methods}

\subsection{Participants}

The cohort was recruited from the Child and Adolescent Psychiatry Unit of the Bambino Gesù Children Hospital, Rome, from 2017 to 2020. A structured assessment was performed during a 3-day evaluation process. The Best Estimate Consensus Diagnosis based on DSM-IV-TR criteria [47] were performed by multidisciplinary groups composed at least by one child psychiatrist and one clinical licensed psychologist according to parent report questionnaires, semi-structured interviews, clinical history, and medical records. Parents or the legal representative of the subjects provided a written, informed consent at a clinic intake for potential research analysis and anonymous reporting of findings in an aggregate form, in accordance with Italian legal and ethical requirements for clinical data.

Thirty-seven individuals with NS were assessed by a multi-method procedure that includes self-report tools and semi structured interviews. Both subjects and at least one of the parents completed the psychopathological assessment. A diagnosis of NS was made by experienced medical geneticists and pediatricians based on a clinical evaluation and was confirmed by molecular analysis.

\subsection{Structured Assessment}

General cognitive abilities were assessed by means of appropriate developmental cognitive tools including Wechsler Intelligence Scale for Children, fourth edition [48], Leiter International Performance Scale Revised (Leiter-R) VR Battery [49], and Raven Coloured Progressive Matrices Test [50]. We classified Intellectual abilities according to DSM-IV-TR [47].

The Schedule for Affective Disorders and Schizophrenia for School Age Children, present and lifetime version (K-SADS-PL) [51] is a semi-structured interview used to assess current and past psychopathological features and psychiatric disorders in children and adolescents according to the DSM-IV-TR criteria [47].

The Children's Depression Rating Scale-Revisited (CDRS-R) [52] is a semi-structured interview used to rate depressive symptoms for ages 6-18 years on 16 items (rated 0 to 3, 4, 5 or 6) with a total score of 18-120 (cut-off clinical positivity > 55). The assessment explores 17 scales: School dysfunctions; difficulties in having fun; difficulties in interpersonal relationships; sleep disorders; appetite disorders; excessive fatigue; psychosomatic complaints; irritability; excessive guilt; low self-esteem; depressive feelings; morbid ideas; suicidal ideation; excessive crying; reduced facial expressions; slow speech; and motor hypoactivity. The CDRS-R clinical positivity cut-offs for the subscale were: $<3$ normal scores; from 3 to 4 borderline scores; and $>4$ clinical scores. "Sleep Disturbance", "Appetite Disturbance", and "Listless Speech" scales have different cut-offs: $<3$ normal scores; 3 borderline scores; and $>3$ clinical scores.

The Kiddie-SADS-Mania Rating Scale (K-SADS-MRS) [53] is a structured interview rating scale used to rate manic symptoms in children and adolescents, composed by 14 scales: Euphoria and expansiveness; irritability and anger; mood liability, reduced need for sleep; crowding thoughts; increased energies; increased activities; motor hyperactivity; grandiosity; speech; distractibility; poor judgment; hallucinations; delusions (considered positive if $>12$ ). The K-SADS-MRS clinical positivity cut-offs were: $>12$ clinical scores; 
subscales cut-off $<2$ normal scores; subscales cut-off $2 / 3$ for borderline scores; and subscales cut-off $>3$ clinical scores.

The Italian version of the Child Behavior Checklist for ages 6 to 18 years (CBCL/618) [54] was completed by the subject's caregivers to rate behavioral and emotional problems in children and adolescents. The CBCL 6-18 is an extensively used tool that provides scores for three broadband behavior rating scales: Internalizing symptoms, externalizing symptoms, and total behavioral problems. The sub-items of these three broadband scales included the eight syndrome scales (withdrawn/depressed, somatic complaints, anxious/depression, social problems, thought problems, attention problems, rule-breaking behaviour, and aggressive behaviour). The CBCL AAA profile was calculated by examining ratings on attention problems, aggression and anxious/depressed scales, is defined as deficient emotional self-regulation (DESR) by a score of $\geq 180$ and $<210(1<\mathrm{SD}<2)$ and as a dysregulation profile (DP) by a score of $>210(>2$ SD) on the sum of three syndromic scales [39].

Participants were globally evaluated by an expert child psychiatrist investigating psychopathological signs / psychiatric disorders according to the criteria of DSM-IV-TR [47], and assessed with rating scales by experienced psychologists. Participants with "traits of disorder" refer to a subsyndromal symptomatology (i.e., NOT fulfilling the DSM-IV-TR criteria for ADHD or anxiety disorders).

\section{Results}

\subsection{Sample Characteristics}

The study included 37 subjects with a genetically confirmed diagnosis of NS. Subjects had a mean $(\mathrm{M})$ age of 11.7 and a standard deviation $(\mathrm{SD}) \pm 2.8$ (age range 7-18 years), 24 (65\%) were males. Twenty-four subjects were heterozygous for mutations in PTPN11, seven carried mutations in SOS1, two in LZTR1, two in RAF1, and one subject was heterozygous for a mutation in RIT1. One subject carried a SHOC2 mutation, which underlies the Mazzanti syndrome, a phenotype clinically related to NS. The cognitive level ranged from moderate impairment to cognitive level on the average $(M \pm$ SD: $88.3 \pm 13.4$; minimum: 48; maximum; 110) (Table 1).

Table 1. Descriptive characteristics of subjects with Noonan syndrome.

\begin{tabular}{ccc}
\hline \multicolumn{2}{c}{ Age, mean (sd) } & $11.7(2.8)$ \\
\hline IQ, mean (sd) & Male & $88.3(13.4)$ \\
\hline Sex, N (\%) & Female & $24(64.9)$ \\
\hline Mutation, N (\%) & LZTR1 & $13(35.1)$ \\
\hline & PTPN11 & $2(5.4)$ \\
\hline & RAF1 & $24(64.9)$ \\
\hline & RIT1 & $2(5.4)$ \\
\hline & SCHOC2 & $1(2.7)$ \\
\hline Diagnosis, N (\%) & SOS1 & $1(2.7)$ \\
\hline & No-one & $7(18.9)$ \\
\hline Anxiety traits & $1(2.9)$ \\
\hline & ADHD traits & $5(13.5)$ \\
\hline & ADHD & $2(5.7)$ \\
\hline & Generalized Anxiety Disorder & $21(60)$ \\
\hline Separation anxiety & $4(11.4)$ \\
\hline & Dysthymia & $3(8.6)$ \\
\hline
\end{tabular}

Legend: N: Number; sd: Standard deviation; IQ: Intelligence quotient. 
The Best Estimate Consensus Diagnosis has revealed that $21(60 \%)$ subjects were diagnosed with ADHD and two subjects showed ADHD traits (6\%), 10 (27\%) subjects were diagnosed with anxiety disorder or anxiety traits, three (9\%) with dysthymia, and one subject was diagnosed with a separation anxiety disorder. Only one patient did not have any psychopathological disorder. A synopsis of prevalence disorders is available in Table 1.

\subsection{Manic and Depressive Symptoms across Groups}

Descriptive statistics were calculated for CDRS-R total scores, K-SADS-MRS scores, and AAA profile scores. To better characterize the presence of depressive and manic symptoms across clinical groups, the percentage of participants above and below the cutoff of CDRS-R (CDRS-R+ and CDRS-R - , respectively) and K-SADS-MRS (K-SADS-MRS+ and K-SADS-MRS-, respectively) were elaborated. About half of the subjects $(n=18,49 \%)$ had clinically significant depressive symptoms as rated with the CDRS-R scale, and the CDRS-R total score was $\mathrm{M} \pm \mathrm{SD}: 53.6 \pm 8.4$.

Sixteen percent of the subjects $(n=6,16 \%)$ had clinically significant (hypo)manic symptoms as rated with the K-SADS-MRS scale, and the K-SADS-MRS total score was $\mathrm{M} \pm \mathrm{SD}: 6.73 \pm 4.30$.

Moreover, almost half of the subjects $(n=16,46 \%)$ showed a clinically significant Emotional Dysregulation as measured with the CBCL-AAA profile, with a CBCL-AAA score of $\mathrm{M} \pm \mathrm{SD}: 184.4 \pm 21.9$ (see Table 2).

Table 2. Descriptive statistics for the questionnaire and interviews score.

\begin{tabular}{|c|c|}
\hline Depression Severity, N (\%) & \\
\hline$C D R S-R+(T$-score $\geq 55)$ & $18(48.6)$ \\
\hline$C D R S-R-(T$-score $<55)$ & $19(51.4)$ \\
\hline \multicolumn{2}{|l|}{ Depression Severity, mean (sd) } \\
\hline CDRS-R total score & $53.6(8.4)$ \\
\hline \multicolumn{2}{|l|}{ Mania/Hypomania Symptoms, N (\%) } \\
\hline$K-S A D S-M R S+(\geq 12)$ & $6(16.2)$ \\
\hline$K-S A D S-M R S-(<12)$ & $31(83.8)$ \\
\hline \multicolumn{2}{|l|}{ Mania/Hypomania Symptoms, mean (sd) } \\
\hline$K-S A D S-M R S$ total score & $6.73(4.3)$ \\
\hline AAA Profile, N (\%) & \\
\hline Deficient Emotional Self-Regulation (DERS; $\geq 180<210$ ) & $11(30)$ \\
\hline Dysregulation Profile $(D P ;>210)$ & $6(16)$ \\
\hline \multicolumn{2}{|l|}{ AAA Profile, means (sd) } \\
\hline AAA score & $184.4(21.9)$ \\
\hline
\end{tabular}

Figures 1 and 2 show a prevalence of depressive symptoms, in CDRS-R+ and CDRS$\mathrm{R}$ - groups, respectively, while Figures 3 and 4 show a prevalence of manic symptoms in K-SADS-MRS+ and K-SADS-MRS- groups, respectively.

\subsubsection{Depressive Symptoms}

As stated, above eighteen individuals (49\%) were considered to have significant depressive symptoms as rated with the CDRS-R rating scale (CDRS-R score >55; total score $M \pm S D: 60 \pm 3.9$ ). The subscales suggestive of clinical depressive symptomatology were: "Impaired schoolwork", "Difficult having fun", "Irritability", "Low self-esteem", and "Depressive feeling". Specifically, one individual (5.6\%) reported clinical scores, and eight $(44.4 \%)$ reported borderline scores in the "Impaired schoolwork" subscale (M \pm SD: $2.3 \pm 1.4)$; four individuals $(22.2 \%)$ reported clinical scores, and six individuals (33.3\%) reported borderline scores in the "Difficult having fun" subscale (M \pm SD: $3.0 \pm 1.0$ ); four individuals $(22.2 \%)$ reported clinical scores and 11 patients $(61.1 \%)$ reported borderline scores in the "Irritability" subscale (M \pm SD: $3.27 \pm 1.5)$; three patients (16.7\%) reported 
clinical scores and six (33.3\%) obtained borderline scores in the "Low self-esteem" subscale $(\mathrm{M} \pm \mathrm{SD}: 2.7 \pm 1.4) ; 11$ patients $(61.1 \%)$ obtained borderline scores in the "Depressive feeling" subscale ( $M \pm \mathrm{SD}: 2.6 \pm 0.10)$. Among all those who presented a clinical depressive symptomatology, four individuals $(22.2 \%)$ have reported a clinically significant suicidal ideation $(\mathrm{M} \pm \mathrm{SD}: 1.5 \pm 0.8)$ (see Figure 1).

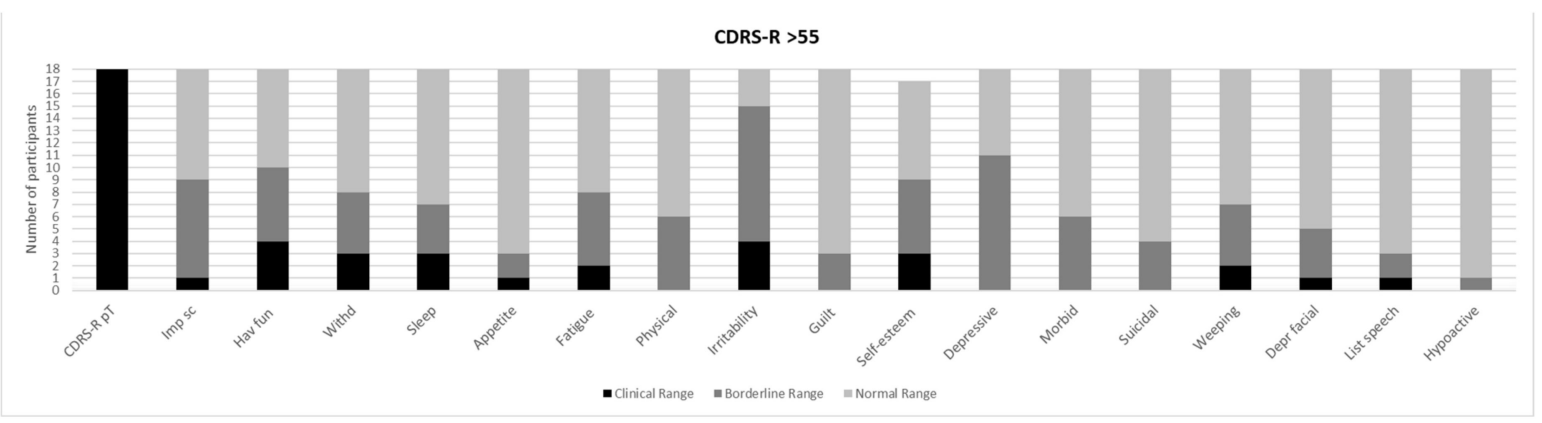

Figure 1. Prevalence of depressive symptoms in the children's depression rating scale (CDRS-R) > 55 (CDRS-R+). Imp sc: Impaired schoolwork; Hav fun; Difficult having fun; Withd: Social withdrawal; Sleep: Sleep disturbance; Appetite: Appetite disturbance; Fatigue: Excessive fatigue; Physical: Physical complaints; Guilt: Excessive guilt; Self-esteem: Low self-esteem; Depressive: Depressive feeling; Morbid: Morbid ideation; Suicidal: Suicidal ideation; Weeping: Excessive weeping; Depr facial: Depressed facial affect; List speech: Listless speech.

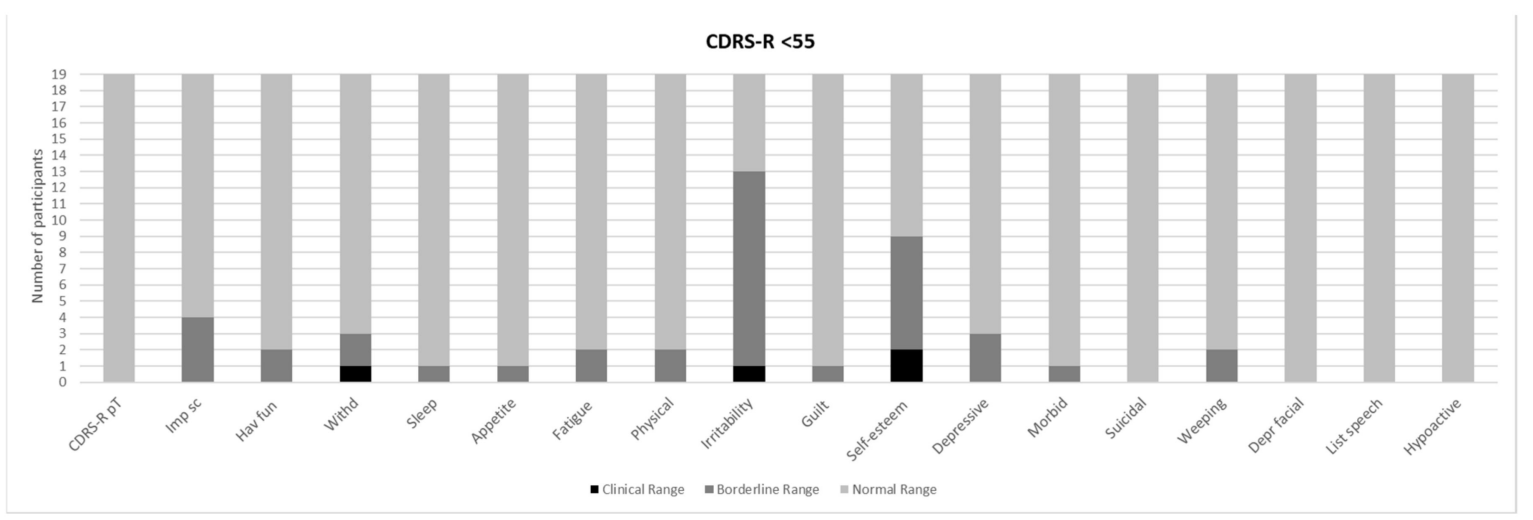

Figure 2. Prevalence of depressive symptoms in CDRS-R < 55 (CDRS-R-). Imp sc: Impaired schoolwork; Hav fun; Difficult having fun; Withd: Social withdrawal; Sleep: Sleep disturbance; Appetite: Appetite disturbance; Fatigue: Excessive fatigue; Physical: Physical complaints; Guilt: Excessive guilt; Self-esteem: Low self-esteem; Depressive: Depressive feeling; Morbid: Morbid ideation; Suicidal: Suicidal ideation; Weeping: Excessive weeping; Depr facial: Depressed facial affect; List speech: Listless speech.

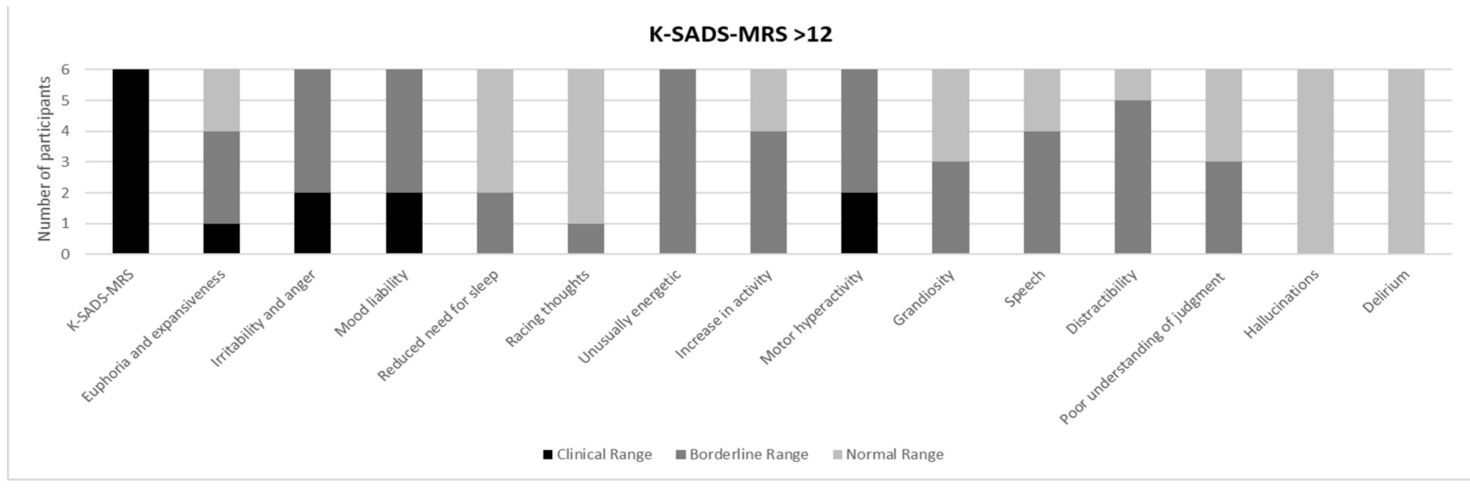

Figure 3. Prevalence of manic symptoms in the schedule for affective disorders and schizophrenia for school age children (K-SADS-MRS) > 12 (K-SADS-MRS+). 


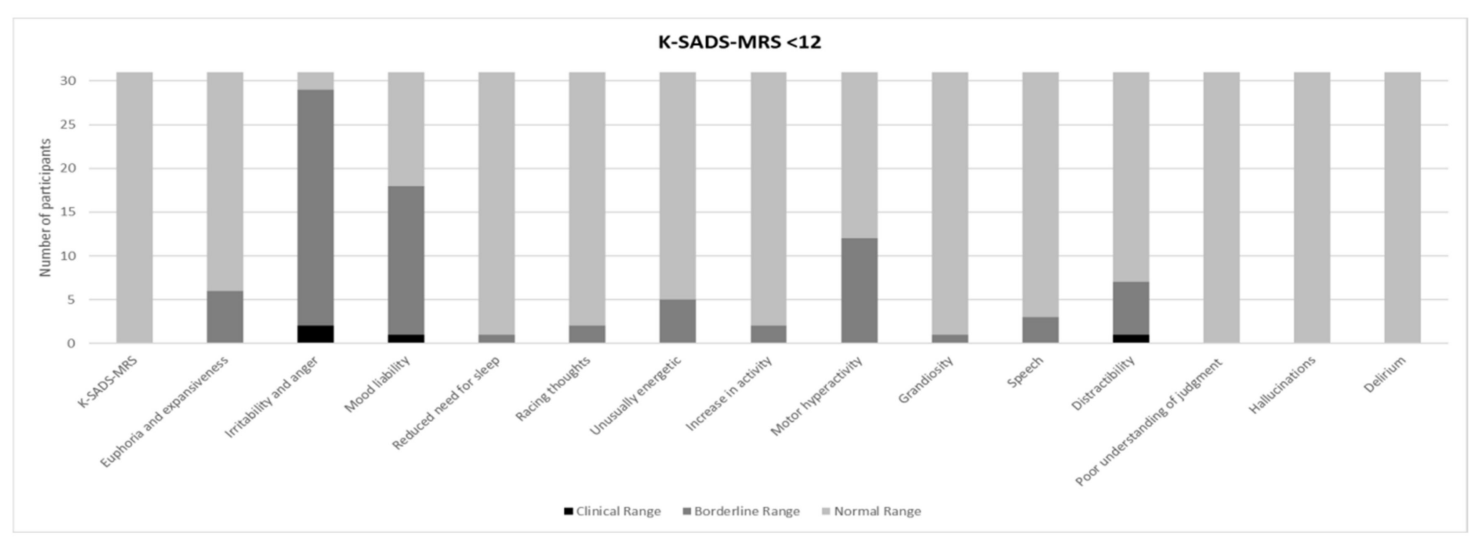

Figure 4. Prevalence of manic symptoms in K-SADS-MRS < 12 (K-SADS-MRS-).

Nineteen individuals (51\%) obtained a normal score (CDRS-R $-<55$; a total score of $\mathrm{M} \pm \mathrm{SD}: 47.5 \pm 6.9$ ). Despite this, the subscales "Irritability" and "Low self-esteem" were suggestive of clinical depressive symptomatology. In particular, one individual (5.3\%) obtained a clinical score and 12 individuals (63.2\%) obtained borderline scores in the "Irritability" subscale (M \pm SD: $2.9 \pm 0.10)$; two individuals (10.5\%) obtained clinical scores and seven $(36.8 \%)$ obtained borderline scores in the "Low self-esteem" subscale (M \pm SD: $2.4 \pm 1.3$ ) (see Figure 2).

\subsubsection{Manic Symptoms}

As stated above, six individuals (16\%) obtained clinically significant scores (K-SADSMRS $+>12$ total score $\mathrm{M} \pm \mathrm{SD}: 15.16 \pm 2.13$ ). The subscales suggestive of clinical (hypo) manic symptoms were: "Euphoria expansiveness", "Irritability and anger", "Mood liability", "Unusually energetic", "Increase in activities", "Motor hyperactivity", "Speech", and "Distractibility". Specifically, one individual (16.7\%) reported a clinical score, and three (50\%) obtained a clinical score in the "Euphoria expansiveness" subscale ( \pm SD: $2.16 \pm 1.16)$; two individuals (33.3\%) obtained clinical scores and four individuals $(66.7 \%)$ obtained borderline scores in the "Irritability and anger" subscale (M \pm SD: $3.3 \pm 0.5)$; two individuals (33.3\%) obtained clinical scores and four individuals $(66.7 \%)$ obtained borderline scores in the "Mood liability" subscale (M \pm SD: $3.3 \pm 1.03)$; six individuals (100\%) obtained borderline scores in the "Unusually energetic" subscale (M $\pm \mathrm{SD}: 2.3 \pm 0.5$ ); four individuals $(66.7 \%)$ obtained borderline scores in the "Increase in activities" subscale $(\mathrm{M} \pm \mathrm{SD}: 1.7 \pm 0.5)$; two individuals (33.3\%) obtained clinical scores and four individuals $(66.7 \%)$ obtained borderline scores in the "Motor hyperactivity" subscale $(\mathrm{M} \pm \mathrm{SD}$ : $3.3 \pm 0.5)$; four individuals $(66.7 \%)$ obtained borderline scores in the "Speech" subscale (M \pm SD: $2 \pm 0.8)$ and five (83.3\%) obtained borderline scores in the "Distractibility" subscale ( \pm SD: $2 \pm 0.6$ ) (see Figure 3 ).

Thirty-one individuals $(84 \%)$ obtained a normal score (K-SADS-MRS $+<12)$. Despite that, the subscales "Irritability and anger" and "Mood liability" were suggestive of clinical (hypo) manic symptoms. Specifically, two individuals (6.4\%) obtained clinical scores and $27(87.1 \%)$ obtained borderline scores in the "Irritability and anger" subscale ( \pm SD: $2.5 \pm 0.8)$; one (3.2\%) obtained a clinical score and 17 (54.8\%) obtained borderline scores in the "Mood liability" subscale (M \pm SD: $2 \pm 0.9$ ) (see Figure 4).

It is worth noting that the scores above the borderline/clinical cut-off were found in the "Irritability" CDRS-R scale and "Irritability and Anger" K-SADS-MRS, respectively in $75.67 \%$ and $94.59 \%$ of the whole sample.

\section{Discussion}

The present study aimed to provide a detailed description of psychopathological features in children and adolescents with NS. To the best of our knowledge, this is the first study reporting data on the development of mood symptoms and emotional dys- 
regulation in children diagnosed with NS using a "gold standard" test battery for mood disorder rating.

Consistently with previous studies that were demonstrated in patients with NS, the high frequency of hyperactivity and impairment in attention skills and executive functioning $[3,15,20,21,24,55,56], 66 \%$ of the subjects were diagnosed with ADHD diagnosis or traits.

Although only $9 \%$ of the subjects were diagnosed with a mood disorder (dysthymia) following the DSM-IV criteria, half of the children $(n=18,49 \%$ of the total sample) were found to have a clinically significant depressive symptomatology when rated with the CDRS-R, the "gold standard" rating scale to assess depressive symptoms in children and adolescents (Table 2, Figure 1). Among subjects with a clinically meaningful depressive symptomatology, the irritability, anhedonia, school impairment, low self-esteem, and depressive feelings were the most commonly reported symptoms (Table 2, Figure 1). Furthermore, about $22 \%$ of subjects with a clinical depressive symptomatology reported suicidal ideation (see Figure 1). Of note, irritability and low self-esteem were rated as clinically significant in $73 \%$ and $50 \%$, respectively of the NS subjects in our sample.

We identified that $16 \%$ of the subjects showed clinically significant scores at the manic symptoms' rating with the K-SADS-MRS. The more frequently reported symptoms were irritability, mood lability and euphoria, increased energy and activity, motor hyperactivity and pressured speech, as well as mood lability. Among these, about two thirds of the subjects were found to be frequently euphoric, almost all of them scored significantly in irritability and mood lability, and borderline in highly energetic. Of note, $95 \%$ of the total number of subjects reported a clinically significant irritability and $65 \%$ a clinically significant mood lability, as rated with the K-SADS-MRS.

Those findings underline an impressive prevalence of subsyndromal manic, depressive, and mixed symptomatology in children with NS, mostly clinically diagnosed with ADHD, but showing mood and behavioral alterations, with an uncommon similarity among the subjects, and far beyond the simple clinical picture of a classic ADHD.

Indeed, nearly a half ( $46 \%$ ) of our cohort with NS shows at least a DESR profile (dysregulation profile or deficient emotional self-regulation), highlighting emotional dysregulation problems as a relatively common feature. This latter finding confirms the general clinical evidence that subjects with ADHD (with and without genetic syndromes) often show emotional dysregulation $[37,39,43-46]$, and raise questions on the psychopathological characterization and the future development of this unspecific clinical feature. Some authors have reported that a very severe dysregulation profile rated with CBCL-AAA is highly related with the progression to a full syndromic pediatric bipolar disorder, frequently associated with ADHD [57]. The unusual high prevalence of mood symptoms such as anhedonia, low self-esteem, mood lability, and irritability in this sample of NS subjects, together with ADHD and severe emotional dysregulation need further evaluation to assess if they can be considered phenotypical characteristics of this genetic syndrome [23].

Our findings also highlighted the presence of depressive symptoms (nearly $50 \%$ with scores above the cut-off in CDRS-R) and manic symptoms (around 16\%), even if only $9 \%$ of the individuals in our sample satisfied the criteria for mood disorders (dysthymia) according to DSM-IV-TR. The lower percentage of mood disorders clinically diagnosed in our cohort could be due to the relatively young mean age (11.7 years) of our subjects and to the probable tendency towards an underdiagnosis of mood disorders when they onset with a prevalent mood dysregulation, unclear episodes, and rapid mood shifts. The high prevalence of irritability, mood lability with rapid mood shifts, and subsyndromal depressive symptoms such as anhedonia and low self-esteem (see Figures 1-4) have been largely reported as a risk factor for the development of major depressive and bipolar disorders later in life, frequently associated with high morbidity, disability, and comorbid substance and anxiety disorders [58]. Given these associations [23], a careful psychiatric follow-up of these symptoms is important over time. 
Another important finding is that $28 \%$ of our sample have anxious symptomatology, consistent with previous findings describing a high prevalence of anxiety traits and ADHD in children with NS when compared to the general population [19]. Several authors have reported that anxious symptoms are important predictors of future development of depressive disorders, and an increased risk of worse outcomes of depressive episodes in terms of greater depressive long term morbidity as well as an increased risk in suicidal behavior [44-46,59]. Indeed, several studies have reported a high prevalence of depressive disorders in adults diagnosed with NS [1,21,29], and a high prevalence of NS subjects have been reported to need an antidepressant treatment during adult ages [21].

Considering the large amount of evidence of a high risk for depressive episodes in adults with NS, we hypothesized that there might be a continuity between the severe mooddysregulation with subsyndromal depressive and (hypo)manic symptoms observed in childhood [15,18-20,24,25,32,36,44], and the depressive episodes described in adults with NS. Longitudinal studies are needed to explore whether irritability and the DESR profile contribute to mood disorders in children with NS, and whether they have a predictive value of future development of a mood disorder in adult ages.

\section{Conclusions}

In conclusion, this research highlights the presence of subsyndromal depressive symptoms (irritability, anhedonia, school impairment, low self-esteem, depressive feelings, suicidal ideation), as well as (hypo)manic symptoms (irritability, mood lability, euphoria, increased energy and activity, motor hyperactivity, pressured speech, and mood lability) in NS. Furthermore, nearly a half of our patients showed a dysregulation profile or deficient emotional self-regulation.

Despite the fact that ADHD is the most frequent diagnosis in our sample, the presence of subsyndromal depressive and (hypo)manic symptoms seems to be far beyond the simple clinical picture of a classic ADHD. A longitudinal observation of clinical symptoms evolution in these patients would allow a further comprehension of the linkage between the combination of symptoms and clear depressive or manic diagnoses.

\section{Limitations}

Our study is not without limitations, the major being an absence of a control sample. Furthermore, the relatively small size of our sample does not allow for a systematic statistical analysis of the correlation between the genotype and behavioural phenotype. Moreover, given the relatively small sample size, gender differences have not been explored in this study. Finally, "hyperactivity" has been addressed by means of a semi-structured interview (K-SADS-PL) [51]. The hyperactivity diagnosis has been performed by multidisciplinary groups composed at least of one child psychiatrist and one clinical licensed psychologist according to the DSM-IV-TR criteria [47] based on semi-structured interviews and clinical history. However, further studies using specific diagnostic tools (such as Conners Parent Rating Scale-Revised and Conners Teacher Rating Scale-Revised) [60] would improve the characterization of these symptoms.

Author Contributions: Conceptualization, P.A., F.C. (Francesca Cumbo), and G.S.; methodology, P.A., F.C. (Francesca Cumbo), and G.S.; software, C.F. and M.T. (Monia Trasolini); validation, G.S. and C.F.; formal analysis, C.F., F.S., and C.C.; investigation, F.C. (Francesca Cumbo), F.C. (Flavia Cirillo), M.P.C., G.S., C.F., M.T. (Monia Trasolini), and S.L.; resources, P.A., G.S., M.C.D., and R.C.; data curation, C.F., F.C. (Francesca Cumbo)., and M.T. (Monia Trasolini); writing-original draft preparation, P.A., F.C. (Francesca Cumbo), and G.S.; writing-review and editing, P.A., F.C. (Francesca Cumbo), G.S., M.T. (Marco Tartaglia), and S.V.; visualization, C.C. and A.D.; supervision, P.A., M.T. (Marco Tartaglia), R.C., M.C.D., and S.V.; project administration, P.A., S.V., and M.T. (Marco Tartaglia); funding acquisition, M.T. (Marco Tartaglia). All authors have read and agreed to the published version of the manuscript.

Funding: Italian Ministry of Health (Ricerca Corrente, to M.T. (Marco Tartaglia)). 
Institutional Review Board Statement: The study was conducted according to the guidelines of the Declaration of Helsinki, and approved by IRCCS Ospedale Pediatrico Bambino Gesù (protocol code 1412_OPBG_2017; 10-04-2017).

Informed Consent Statement: Informed consent was obtained from all the subjects involved in the study.

Data Availability Statement: The data that support the findings of this study are available on request from the corresponding author. The data are not publicly available due to privacy or ethical restrictions.

Acknowledgments: We wish to thank all the patients and their families for their participation in the study.

Conflicts of Interest: The authors declare no conflict of interest.

\section{References}

1. Shaw, A.C.; Kalidas, K.; Crosby, A.H.; Jeffery, S.; Patton, M.A. The natural history of Noonan syndrome: A long-term follow-up study. Arch. Dis. Child. 2007, 92, 128-132. [CrossRef]

2. Sharland, M.; Burch, M.; McKenna, W.M.; Paton, M.A. A clinical study of Noonan syndrome. Arch. Dis. Child. 1992, 67, 178-183. [CrossRef]

3. Allanson, J.E. Noonan syndrome. J. Med. Genet. 1987, 24, 9-13. [CrossRef]

4. Roberts, A.E.; Allanson, J.E.; Tartaglia, M.; Gelb, B.D. Noonan syndrome. Lancet 2013, 381, 333-342. [CrossRef]

5. Tartaglia, M.; Mehler, E.L.; Goldberg, R.; Zampino, G.; Brunner, H.G.; Kremer, H.; van der Burgt, I.; Crosby, A.H.; Ion, A.; Jeffery, S.; et al. Mutations in PTPN11, encoding the protein tyrosine phosphatase SHP-2, cause Noonan syndrome. Nat. Genet. 2001, 29, 465-468. [CrossRef]

6. Altmüller, F.; Lissewski, C.; Bertola, D.; Flex, E.; Stark, Z.; Spranger, S.; Baynam, G.; Buscarilli, M.; Dyack, S.; Gillis, J.; et al. Genotype and phenotype spectrum of NRAS germline variants. Eur. J. Hum. Genet. 2017, 25, 823-831. [CrossRef] [PubMed]

7. Lissewski, C.; Chune, V.; Pantaleoni, F.; de Luca, A.; Capri, Y.; Brinkmann, J.; Lepri, F.; Daniele, P.; Leenders, E.; Mazzanti, L.; et al. Variants of SOS2 are a rare cause of Noonan syndrome with particular predisposition for lymphatic complications. Eur. J. Hum. Genet. 2020. [CrossRef] [PubMed]

8. Capri, Y.; Flex, E.; Krumbach, O.; Carpentieri, G.; Cecchetti, S.; Lißewski, C.; Rezaei Adariani, S.; Schanze, D.; Brinkmann, J.; Piard, J.; et al. Activating mutations of RRAS2 are a rare cause of noonan syndrome. Am. J. Hum. Genet. 2019, 104, 1223-1232. [CrossRef] [PubMed]

9. Motta, M.; Sagi-Dain, L.; Krumbach, O.; Hahn, A.; Peleg, A.; German, A.; Lissewski, C.; Coppola, S.; Pantaleoni, F.; Kocherscheid L.; et al. Activating MRAS mutations cause Noonan syndrome associated with hypertrophic cardiomyopathy. Hum. Mol. Genet. 2020, 29, 1772-1783. [CrossRef]

10. Motta, M.; Pannone, L.; Pantaleoni, F.; Bocchinfuso, G.; Radio, F.C.; Cecchetti, S.; Ciolfi, A.; di Rocco, M.; Elting, M.W.; Brilstra, E.H.; et al. Enhanced MAPK1 function causes a neurodevelopmental disorder within the RASopathy clinical spectrum. Am. J. Hum. Genet. 2020, 107, 499-513. [CrossRef]

11. Rauen, K.A. The RASopathies. Annu. Rev. Genom. Hum. Genet. 2013, 14, 355-369. [CrossRef] [PubMed]

12. Tartaglia, M.; Gelb, B.D. Disorders of dysregulated signal traffic through the RAS-MAPK pathway: Phenotypic spectrum and molecular mechanisms. Ann. N. Y. Acad. Sci. 2010, 1214, 99-121. [CrossRef] [PubMed]

13. Tartaglia, M.; Gelb, B.D.; Zenker, M. Noonan syndrome and clinically related disorders. Best Pract. Res. Clin. Endocrinol. Metab. 2011, 25, 161-179. [CrossRef] [PubMed]

14. Pierpont, E.I. Neuropsychological functioning in individuals with noonan syndrome: A systematic literature review with educational and treatment recommendations. J. Pediatric Neuropsychol. 2016, 2, 14-33. [CrossRef]

15. Cesarini, L.; Alfieri, P.; Pantaleoni, F.; Vasta, I.; Cerutti, M.; Petrangeli, V.; Mariotti, P.; Leoni, C.; Ricci, D.; Vicari, S.; et al. Cognitive profile of disorders associated with dysregulation of the RAS/MAPK signaling cascade. Am. J. Med. Genet. A 2009, 149A, 140-146. [CrossRef]

16. Alfieri, P.; Cesarini, L.; Mallardi, M.; Piccini, G.; Caciolo, C.; Leoni, C.; Mirante, N.; Pantaleoni, F.; Digilio, M.C.; Gambardella, M.L.; et al. Long term memory profile of disorders associated with dysregulation of the RAS-MAPK signaling cascade. Behav. Genet. 2011, 41, 423-429. [CrossRef]

17. Lepri, F.; de Luca, A.; Stella, L.; Rossi, C.; Baldassarre, G.; Pantaleoni, F.; Cordeddu, V.; Williams, B.J.; Dentici, M.L.; Caputo, V.; et al. SOS1 mutations in Noonan syndrome: Molecular spectrum, structural insights on pathogenic effects, and genotype-phenotype correlations. Hum. Mutat. 2011, 32, 760-772. [CrossRef] [PubMed]

18. Garg, S.; Brooks, A.; Burns, A.; Burkitt-Wright, E.; Kerr, B.; Huson, S.; Emsley, R.; Green, J. Autism spectrum disorder and other neurobehavioural comorbidities in rare disorders of the Ras/MAPK pathway. Dev. Med. Child Neurol. 2017, 59, 544-549. [CrossRef] [PubMed]

19. Perrino, F.; Licchelli, S.; Serra, G.; Piccini, G.; Caciolo, C.; Pasqualetti, P.; Cirillo, F.; Leoni, C.; Digilio, M.C.; Zampino, G.; et al. Psychopathological features in Noonan syndrome. Eur. J Paediatric Neurol. 2018, 22, 170-177. [CrossRef] [PubMed] 
20. Lee, D.A.; Portnoy, S.; Hill, P.; Gillberg, C.; Patton, M.A. Psychological profile of children with Noonan syndrome. Dev. Med. Child Neurol. 2005, 47, 35-38. [CrossRef]

21. Verhoeven, W.; Wingbermühle, E.; Egger, J.; van der Burgt, I.; Tuinier, S. Noonan syndrome: Psychological and psychiatric aspects. Am. J. Med. Genet. A 2008, 146A, 191-196. [CrossRef] [PubMed]

22. Eyre, O.; Langley, K.; Stringaris, A.; Leibenluft, E.; Collishaw, S.; Thapar, A. Irritability in ADHD: Associations with depression liability. J. Affect. Disord. 2017, 215, 281-287. [CrossRef]

23. Eyre, O.; Riglin, L.; Leibenluft, E.; Stringaris, A.; Collishaw, S.; Thapar, A. Irritability in ADHD: Association with later depression symptoms. Eur. Child Adolesc. Psychiatry 2019, 28, 1375-1384. [CrossRef] [PubMed]

24. Allanson, J.E. Noonan syndrome. Am. J. Med. Genet. C Semin. Med. Genet. 2007, 145C, 274-279. [CrossRef]

25. Alfieri, P.; Piccini, G.; Caciolo, C.; Perrino, F.; Gambardella, M.L.; Mallardi, M.; Cesarini, L.; Leoni, C.; Leone, D.; Fossati, C.; et al Behavioral profile in RASopathies. Am. J. Med. Genet. A 2014, 164A, 934-942. [CrossRef] [PubMed]

26. Mahendran, R.; Aw, S.C. Noonan's syndrome with mental retardation presenting with an affective disorder-Case report. Singap. Med. J. 1989, 30, 306-307.

27. Krishnan, K.R.R.; Ritchie, J.C.; Tupler, L.A., Jr.; McDonald, W.M.; Knight, D.; Nemeroff, C.B.; Marcovina, S. Apolipoprotein E epsilon 4. Neurology 1994, 44, 2420-2421. [CrossRef]

28. Verhoeven, W.M.; Hendrikx, J.L.; MDoorakkers, M.C.; Egger, J.I.; van der Burgt, I.; Tuinier, S. Alexithymia in Noonan syndrome. Genet. Couns. 2004, 15, 47-52.

29. Roelofs, R.L.; Wingbermühle, E.; van der Heijden, P.T.; Jonkers, R.; de Haan, M.; Kessels, R.; Egger, J. Personality and psychopathology in adults with Noonan Syndrome. J. Clin. Psychol. Med. Settings 2020, 27, 256-267. [CrossRef]

30. Smpokou, P.; Tworog-Dube, E.; Kucherlapati, R.S.; Roberts, A.E. Medical complications, clinical findings, and educational outcomes in adults with Noonan syndrome. Am. J. Med. Genet. A 2012, 158A, 3106-3111. [CrossRef] [PubMed]

31. Allanson, J.E.; Roberts, A.E. Noonan Syndrome. In Gene Reviews; Adam, M.P., Ardinger, H.H., Pagon, R.A., Wallace, S.E., Bean, L.J.H., Mirzaa, G., Amemiya, A., Eds.; University of Washington: Seattle, WA, USA, 1993.

32. Wingbermuehle, E.; Egger, J.; van der Burgt, I.; Verhoeven, W. Neuropsychological and behavioral aspects of Noonan syndrome. Horm. Res. 2009, 72, 15-23. [CrossRef]

33. Faraone, S.V.; Rostain, A.L.; Blader, J.; Busch, B.; Childress, A.C.; Connor, D.F.; Newcorn, J.H. Practitioner review: Emotional dysregulation in attention-deficit/hyperactivity disorder-Implications for clinical recognition and intervention. J. Child Psychol. Psychiatry 2019, 60, 133-150. [CrossRef] [PubMed]

34. Barkley, R.A. Emotional dysregulation is a core component of ADHD. In Attention-Deficit Hyperactivity Disorder: A Handbook for Diagnosis and Treatment; Barkley, R.A., Ed.; The Guilford Press: New York, NY, USA, 2015; pp. 81-115.

35. Gottman, J.M.; Katz, L.F. Effects of marital discord on young children's peer interaction and health. Dev. Psychol. 1989, 25, 373-381. [CrossRef]

36. Donfrancesco, R.; Innocenzi, M.; Marano, A.; Biederman, J. Deficient emotional self-regulation in ADHD assessed using a unique profile of the child behavior checklist (CBCL): Replication in an Italian study. J. Atten. Disord. 2015, 19, 895-900. [CrossRef] [PubMed]

37. Spencer, T.J.; Faraone, S.V.; Surman, C.B.; Petty, C.; Clarke, A.; Batchelder, H.; Wozniak, J.; Biederman, J. Toward defining deficient emotional self-regulation in children with attention-deficit/hyperactivity disorder using the child behavior checklist: A controlled study. Postgrad. Med. 2011, 123, 50-59. [CrossRef]

38. Biederman, J.; Spencer, T.; Lomedico, A.; Day, H.; Petty, C.R.; Faraone, S.V. Deficient emotional self-regulation and pediatric attention deficit hyperactivity disorder: A family risk analysis. Psychol. Med. 2012, 42, 639-646. [CrossRef] [PubMed]

39. Biederman, J.; Petty, C.R.; Monuteaux, M.C.; Evans, M.; Parcell, T.; Faraone, S.V.; Wozniak, J. The child behavior checklist-pediatric bipolar disorder profile predicts a subsequent diagnosis of bipolar disorder and associated impairments in ADHD youth growing up: A longitudinal analysis. J. Clin. Psychiatry 2009, 70, 732-740. [CrossRef] [PubMed]

40. Volk, H.E.; Todd, R.D. Does the child behavior checklist juvenile bipolar disorder phenotype identify bipolar disorder? Biol. Psychiatry 2007, 62, 115-120. [CrossRef]

41. Ayer, L.; Althoff, R.; Ivanova, M.; Rettew, D.; Waxler, E.; Sulman, J.; Hudziak, J. Child behavior checklist juvenile bipolar disorder (CBCL-JBD) and CBCL posttraumatic stress problems (CBCL-PTSP) scales are measures of a single dysregulatory syndrome. J. Child Psychol. Psychiatry 2009, 50, 1291-1300. [CrossRef]

42. Hudziak, J.J.; Althoff, R.R.; Derks, E.M.; Faraone, S.V.; Boomsma, D.I. Prevalence and genetic architecture of Child Behavior Checklist-juvenile bipolar disorder. Biol. Psychiatry 2005, 58, 562-568. [CrossRef]

43. Licchelli, S.; Alfieri, P.; Caciolo, C.; Perrino, F.; Mallardi, M.; Veltri, S.; Casini, M.P.; Digilio, M.C.; Selicorni, A.; Zampino, G.; et al. Child Behavior Checklist emotional dysregulation profiles in RASopathies. Neuropsychiatry 2018, 8, 1797-1805.

44. McNeill, A.M.; Hudock, R.L.; Foy, A.; Shanley, R.; Semrud-Clikeman, M.; Pierpont, M.E.; Berry, S.A.; Sommer, K.; Moertel, C.L.; Pierpont, E.I. Emotional functioning among children with neurofibromatosis type 1 or Noonan syndrome. Am. J. Med. Genet. A 2019, 179, 2433-2446. [CrossRef]

45. Bowen, R.; Chavira, D.A.; Bailey, K.; Stein, M.T.; Stein, M.B. Nature of anxiety comorbid with attention deficit hyperactivity disorder in children from a pediatric primary care setting. Psychiatry Res. 2008, 157, 201-209. [CrossRef]

46. Schatz, D.B.; Rostain, A.L. ADHD with comorbid anxiety: A review of the current literature. J. Atten. Disord. 2006, 10, 141-149. [CrossRef] [PubMed] 
47. American Psychiatric Association. Diagnostic and Statistical Manual of Mental Disorders, 4th ed.; Text Revision; American Psychiatric Association: Washington, DC, USA, 2000.

48. Wechsler, D. Wechsler Intelligence Scale for Children, 4th ed.; Psychological Corporation: San Antonio, TX, USA, 2003.

49. Roid, G.H.; Miller, L.J.; Pomplun, M.; Koch, C. Leiter International Performance Scale, 3rd ed.; Western Psychological Services: Los Angeles, CA, USA, 2013.

50. Raven, J.C. CPM Coloured Progressive Matrices; Organizzazioni Speciali: Florence, Italy, 1981.

51. Kaufman, J.; Birmaher, B.; Brent, D.; Rao, U.; Flynn, C.; Moreci, P.; Williamson, D.; Ryan, N. Schedule for affective disorders and schizophrenia for school-age children-present and lifetime version(K-SADS-PL): Initial reliability and validity data. J. Am. Acad. Child. Adolesc. Psychiatry 1997, 36, 980-988. [CrossRef]

52. Poznanski, E.O.; Miller, E.; Salguero, C.; Kelsh, R.C. Preliminary studies of the reliability and validity of the children's depression rating scale. J. Am. Acad. Child. Psychiatry 1984, 23, 191-197. [CrossRef] [PubMed]

53. Axelson, D.; Birmaher, B.J.; Brent, D.; Wassick, S.; Hoover, C.; Bridge, J.; Ryan, N. A preliminary study of the Kiddie Schedule for Affective Disorders and Schizophrenia for School-Age Children mania rating scale for children and adolescents. J. Child. Adolesc. Psychopharmacol. 2003, 13, 463-470. [CrossRef]

54. Achenbach, T.M.; Rescorla, L. Manual for the ASEBA School-Age Forms \& Profiles; University of Vermont: Burlington, VT, USA, 2001.

55. Pierpont, E.I.; Tworog-Dube, E.; Roberts, A.E. Attention skills and executive functioning in children with Noonan syndrome and their unaffected siblings. Dev. Med. Child Neurol. 2015, 57, 385-392. [CrossRef]

56. Wood, A.; Massarano, A.; Super, M.; Harrington, R. Behavioural aspects and psychiatric findings in Noonan's syndrome. Arch. Dis. Child. 1995, 72, 153e5. [CrossRef] [PubMed]

57. Biederman, J.; Petty, C.R.; Day, H.; Goldin, R.L.; Spencer, T.; Faraone, S.V.; Surman, C.B.; Wozniak, J. Severity of the aggression/anxiety-depression/attention child behavior checklist profile discriminates between different levels of deficits in emotional regulation in youth with attention-deficit hyperactivity disorder. J. Dev. Behav. Pediatrics 2012, 33, 236-243. [CrossRef]

58. Faedda, G.L.; Marangoni, C.; Serra, G.; Salvatore, P.; Sani, G.; Vázquez, G.H.; Tondo, L.; Girardi, P.; Baldessarini, R.J.; Koukopoulos, A. Precursors of bipolar disorders: A systematic literature review of prospective studies. J. Clin. Psychiatry 2015, 76, 614-624. [CrossRef] [PubMed]

59. Serra, G.; Koukopoulos, A.; de Chiara, L.; Koukopoulos, A.E.; Sani, G.; Tondo, L.; Girardi, P.; Reginaldi, D.; Baldessarini, R.J. Early clinical predictors and correlates of long-term morbidity in bipolar disorder. Eur. Psychiatry 2017, 43, 35-43. [CrossRef] [PubMed]

60. Conners, C.K. Conners' Rating Scales-Revised: User's Manual; MultiHealth Systems Incorporated: North Tonawanda, NY, USA, 1997. 